
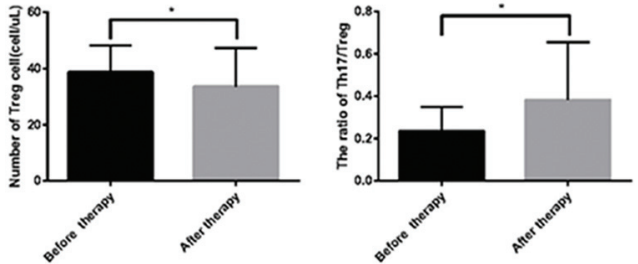

Figure 2. The number of Treg cells and the ratio of Th17/Treg before and after conventional DMARDs therapy.

Disclosure of Interests: None declared

DOI: 10.1136/annrheumdis-2019-eular.6389

\section{SAT0018 THE STUDY OF CD4+T CELL SUBSETS IN RECURRENT POLYCHONDRITIS}

Fang Yuan $\mathrm{Hu}^{1}$, Ning Yan ${ }^{1}$, Jie Liang ${ }^{1}$, Rui Su${ }^{1}$, Chong Gao ${ }^{2}$, LI Xiao-Feng ${ }^{1}$, Caihong Wang $1 .{ }^{1}$ The Second Hospital of Shanxi Medical Univerity, Taiyuan, China; ${ }^{2}$ Department of Pathology, Brigham and Women's Hospital, Harvard Medical School, Boston, MA, United States of America

Background: Relapsing polychondritis (RP) is an rare inflammatory disease of unknown causes, characterized by recurrent inflammation in cartilaginous tissues of the whole body ${ }^{[1]}$. The histologic features of the chondritis include loss of basophilic staining of the cartilage matrix, perichondrial inflammation, cartilage destruction with replacement by fibrous tissue, and perivascular cellular infiltration with plasma cells and lymphocytes. Additional clinical features of the disease include ocular inflammation, vasculitis, audiovestibular dysfunction, myocarditis, cardiac valvular insufficiency, and nonerosive inflammatory arthritis. Many studies have shown that the imbalance of helper $T$ cell 17(Th17) and regulatory $T$ cell (Treg) is involved in the pathogenesis of autoimmune diseases such as SLE and RA. But little is known about the roles of peripheral immune cell subsets peripheral in RP patients. Up to now, just few studies focus on this issue.

Objectives: We aimed to analyse the distribution and phenotype of CD4 $+\mathrm{T}$ cell subsets in the peripheral blood of patients with RP.

Methods: The proportion and absolute counts of circulating immune cells were assessed in 14 patients diagnosed as RP and 14 healthy controls. $\mathrm{CD} 4+\mathrm{T}$ cell subsets were also analysed in 9 untreated RP patients and 9 healthy volunteers by flow cytometry. All statistical analyses were performed with SPSS v. 22.0. Continuous variables were reported as median. For all study variables, comparison among controls and RP subjects was based on the non-parametric Wilcoxon Mann-Whitney exact test. For all analyses, we used two-sided tests, with p-values $<0.05$ denoting statistical significance.

Results: Proportion and absolute counts of Treg cells were significantly reduced in RP patients in comparison with controls (proportion, $3.61 \%$ vs. $5.24 \%, p<0.001$; absolute counts, $27.36 / \mu l$ vs. $46.56 / \mu l, p<0.001)$. But there were no significant difference between the percentage and number of Th17, Th1 or Th2 cells in patients with RP and healthy controls. Thus, the ratio of Th17/Treg increased in RP patients $(0.25$ vs. $0.14, p<0.001)$, as did the ratio of Th2/Treg (0.28 vs. $0.22, p<0.001)$ and Th1/Treg( 2.75 vs. 1.92, $\mathrm{p}=0.019$ )(Figue 1). Similarly, the proportion and absolute counts of Treg cells in untreated RP patients were significantly lower than that in healthy controls (proportion, $3.78 \%$ vs. $5.66 \%, \quad \mathrm{p}=0.008$; absolute counts, $32.24 / \mu \mathrm{l}$ vs. $50.76 / \mu \mathrm{l}, \mathrm{p}<0.001)$. And the ratio of Th17/Treg slso increased in untreated RP patients $(0.25$ vs. $0.15, p=0.003)$, as did the ratio of Th1/Treg (2.35 vs. $1.88, \mathrm{p}=0.014)$ (Figue 2).

Conclusion: Our data suggested that the immune-inflammation in RP patients may be related to the depletion of Treg cells and the imbalance of Th17 or Th1 or Th2 and Treg cells.Reduction of peripheral Treg cells may exacerbate the disease progression by not being inhibited Th cells.

\section{REFERENCE}

[1] Kingdon J, Roscamp J, Sangle S, et al. Relapsing polychondritis: a clinical review for rheumatologists[J]. Rheumatology, 2017, 57(9): 1525-1532.

Acknowledgement: Rheumatology and laboratory staff in the Second Hospital of Shanxi Medical University

Disclosure of Interests: None declared

DOI: 10.1136/annrheumdis-2019-eular.1250
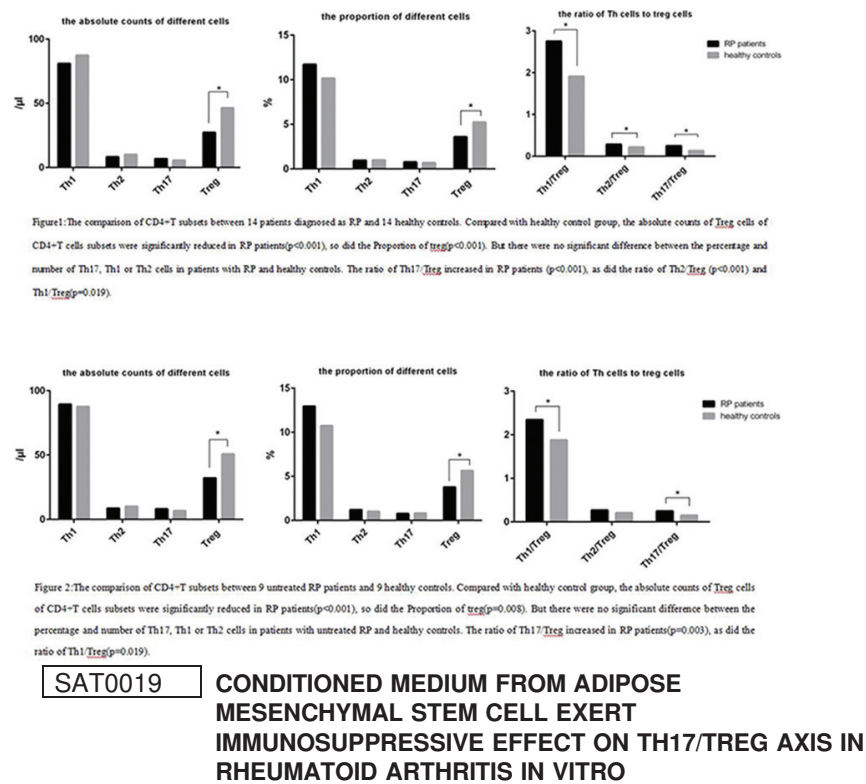

Georgi Vasilev $^{1}$, Mariana Ivanova Goycheva ${ }^{2}$, Ekaterina Ivanova-Todorova ${ }^{1}$, Kalina Tumangelova-Yuzeir ${ }^{1}$, Ekaterina Kurteva ${ }^{1}$, Rumen Stoilov' ${ }^{2}$,

Dobroslav Kyurkchiev ${ }^{1} .{ }^{1}$ Medical Faculty, Medical University, University Hospital "St. Ivan Rilski", Laboratory of Clinical Immunology, Sofia, Bulgaria; ${ }^{2}$ Medical Faculty, Medical University, University Hospital "St. Ivan Rilski", Clinic of Rheumatology, Sofia, Bulgaria

Background: Emerging data have demonstrated that mesenchymal stem cells (MSC) are well endowed with a broad repertoire of immunosuppressive tools and they could modulate the immune response on several levels via production of a plethora of soluble factors and contact-dependent mechanisms. For these reasons, mesenchymal stem cells-based protocols were spotlighted as promising multiple-hit treatment candidates for therapeutic intervention in a multitude of autoimmune diseases and debilitating conditions such as rheumatoid arthritis (RA).

Objectives: In line with aforementioned and taking in mind the current shift in Th1/Th2 paradigm suggesting a key role of Th17/Treg axis dysregulations in RA pathogenesis, we aimed to appraise the immunoregulatory effects of secretory factors produced by adipose-derived MSC (ATMSC) on Th17 and Tregs subsets and also pro-inflammatory cytokines production in patients with RA.

Methods: The study encompasses 17 patients matching the ACR/EULAR 2010 criteria for RA. AT-MSC were isolated and cultured according to well-established protocols. Peripheral blood mononuclear cells (PBMCs) isolated from RA patients' samples were cultured in AT-MSC conditioned media and in control media. Flow cytometry was used for detection of Th17 and Treg markers (of CD3, CD4, CD161, CD196 and CD25 and intracellular expression of FoxP3). ELISA was performed for testing the cytokines produced by PBMC (TGF- $\beta 1$, TNF- $\alpha$, IL-17A, IL-21).

Results: We found significant elevation in percentage of $\mathrm{CD} 4^{+} \mathrm{CD} 25^{+} \mathrm{FoxP}^{+}$Treg cell in the pool of PBMC cultured with AT-MSC as opposed to control medium, $4.22 \pm 2 \%$ (mean \pm SD) vs. $6.04 \pm$ $3.6 \%(p=0.001)$. Paired sample analysis of Th17 cells percentage values from all $\mathrm{CD}^{+}$in PBMC cultured with control media (mean $\pm \mathrm{SD}$ ) $10.13 \pm 3.88 \%$ in contrast to Th17 percentage in PBMC cultured with AT-MSC supernatants $8.98 \pm 3.58 \%$ showed significant decrease in Th17 numbers $(p=0.02)$ under the influence of AT-MSC secretory factors. Cultivation of RA patient's PBMCs with AT-MSC supernatants led to significant up-regulation of TGF- $\beta 1$ levels, (median [IQR]) $8.318 \mathrm{ng} / \mathrm{ml}(6.327$ - $11.686 \mathrm{ng} / \mathrm{ml})$ vs. $6.227 \mathrm{ng} / \mathrm{ml} ;(1.681-10.148 \mathrm{ng} / \mathrm{ml})(p=0.013)$ and decrease in levels of TNF- $\alpha, \mathrm{IL}-17 \mathrm{~A}$, and IL-21 respectively: $5 \mathrm{pg} / \mathrm{ml}$ $(1.75-11.65 \mathrm{pg} / \mathrm{ml})$ vs. $1 \mathrm{pg} / \mathrm{ml}(0.7-1.9 \mathrm{pg} / \mathrm{ml}) \quad(\mathrm{p}=0.001) ; 4.2 \mathrm{pg} /$ $\mathrm{ml}(3.1-6.1 \mathrm{pg} / \mathrm{ml})$ vs. $2.3 \mathrm{pg} / \mathrm{ml}(0.75-5.42 \mathrm{pg} / \mathrm{ml})(\mathrm{p}=0.017) ; 75.1$ $\pm 35.95 \mathrm{pg} / \mathrm{ml}$ vs. $52.09 \pm 30.8 \mathrm{pg} / \mathrm{ml}(\mathrm{p}=0.022)$. The reduction in IL17 levels positively correlated with the decrease of TNF- $\alpha(r=0.921, p$ $=0.001$.

Conclusion: Our study unambiguously demonstrated that secretory factors produced by AT-MSC exert an immunoregulatory effect on Th17 and Treg cells and also could inhibit major effector cytokine pathways: TNF- $\alpha$, IL-17, IL-21 production in RA in vitro. The study of mechanisms of immunoregulation induced by MSCs provide us better insight into the pathogenesis of rheumatoid arthritis and could be a potential therapeutic approach. 